\title{
Проявление Хатангско-Ломоносовской зоны разломов в дифференцированных геолого-геофизических показателях
}

\author{
Шипилов Э.В. \\ Полярный геофизический институт, Мурманск, shipilov@pgi.ru
}

Аннотация. Рассмотрено отражение Хатангско-Ломоносовской зоны разломов в спектре результатов полученных в ходе проведения исследований разнородными геолого-геофизическими методами. Проиллюстрирована связь зоны разломов с полосами градиентов распределения изолиний S-скорости как функции глубины, с повышенными значениями теплового потока, с особенностями распределением эпицентров землетрясений, а также с приуроченностью сиповых полей разгрузки метана.

Ключевые слова: Хатангско-Ломоносовская зона разломов, линеамент, волны Рэлея, тепловой поток, эпицентры землетрясений, метановые сипы.

\section{Manifestation of the Khatanga-Lomonosov fault zone in differentiated geological and geophysical indicators}

\author{
Shipilov E.V. \\ Polar Geophysical Institute, Murmansk, shipilov@pgi.ru
}

\begin{abstract}
The reflection of the Khatanga-Lomonosov fault zone in the spectrum of the results obtained in the course of research by different geological and geophysical methods is considered. The relationship of the fault zone with the bands of gradients of the distribution of S-velocity isolines as a function of depth, with increased values of the heat flow, with the peculiarities of the distribution of earthquake epicenters, as well as with the confinement of sip fields of methane unloading is illustrated.
\end{abstract}

Key words: Khatanga-Lomonosov fault zone, lineament, Rayleigh waves, heat flow, earthquake epicenters, methane seeps.

\section{Введение}

Тектонические элементы зоны сопряжения Лаптевоморской континентальной окраины с прилегающим глубоководным ложем Арктики перекрыты мощным осадочным чехлом мелкайнозойского возраста. Тем не менее, среди них только Хатангско-Ломоносовская окраинноконтинентальная полоса разломов (ХЛЗ) получила отчетливое отражение в рельефе дна рассматриваемой континентальной окраины в виде наиболее заметного линеамента тяготеющего к бровке шельфа. Линеамент прослеживается из Хатангского залива в северо-восточном направлении в район сочленения хр. Ломоносова с континентальной окраиной.

Как показывает анализ структуры аномальных геофизических полей и результатов сейсмических исследований (Шипилов и др., 2019; 2020), ХЛЗ представлена серией эшелонированных или кулисообразно расположенных субпараллельных разломов различной амплитуды и комбинированной кинематики.

И в этой связи в дополнение к изложенным ранее характеристикам (Шипилов и др., 2019; Шипилов, Кириллова, 2020) следует добавить ее отображение в глубинной структуре и в других геофизических параметрах.

\section{Геолого-геофизические характеристики ХЛз}

Проведенный анализ групповых скоростей волн Рэлея в литосфере Арктики с построением схем распространения S-скорости как функции глубины (Corchete, 2019) показывает, что ХЛЗ находит отражение в появлении отчетливых полос градиентов распределения скоростей в диапазонах глубин около 10 км. Выше этого уровня, т.е. в верхней части осадочного чехла, таких градиентов не наблюдается, но они явно прорисовываются в интервалах, приуроченных к низам осадочного чехла, на уровне фундамента и вплоть до подошвы земной коры (рис. 1). По меньшей мере, это указывает на коровый ранг зоны разломов. 
a

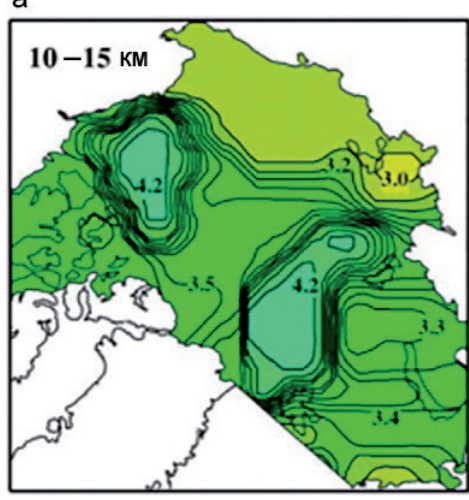

6

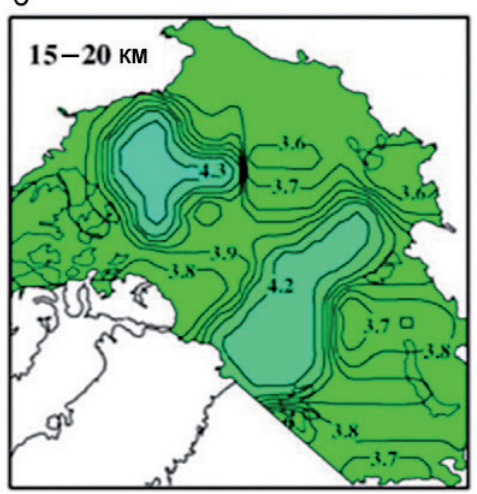

B

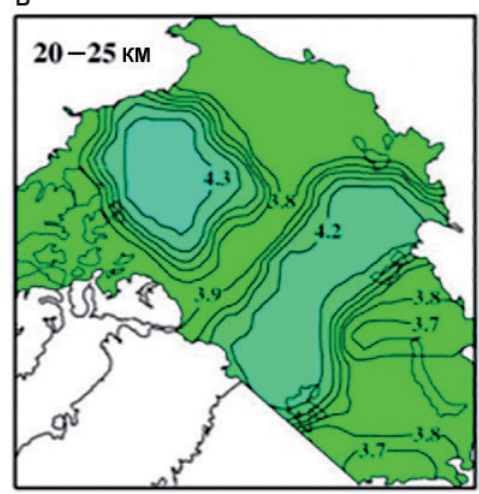

\section{$\beta(\mathrm{KM} / \mathrm{C})$}

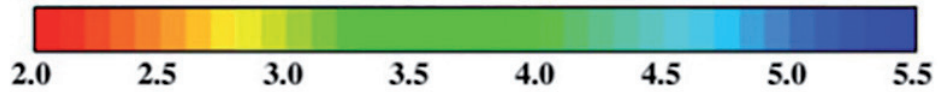

Рис. 1. Географическое распределение S-скорости как функции глубины. Интервал между изолиниями $0.1 \mathrm{\kappa м} / \mathrm{c}$ (Corchete, 2017).

Fig. 1. Geographic distribution of S-velocity as a function of depth. The contour interval is $0.1 \mathrm{~km} / \mathrm{s}$ (Corchete, 2017).

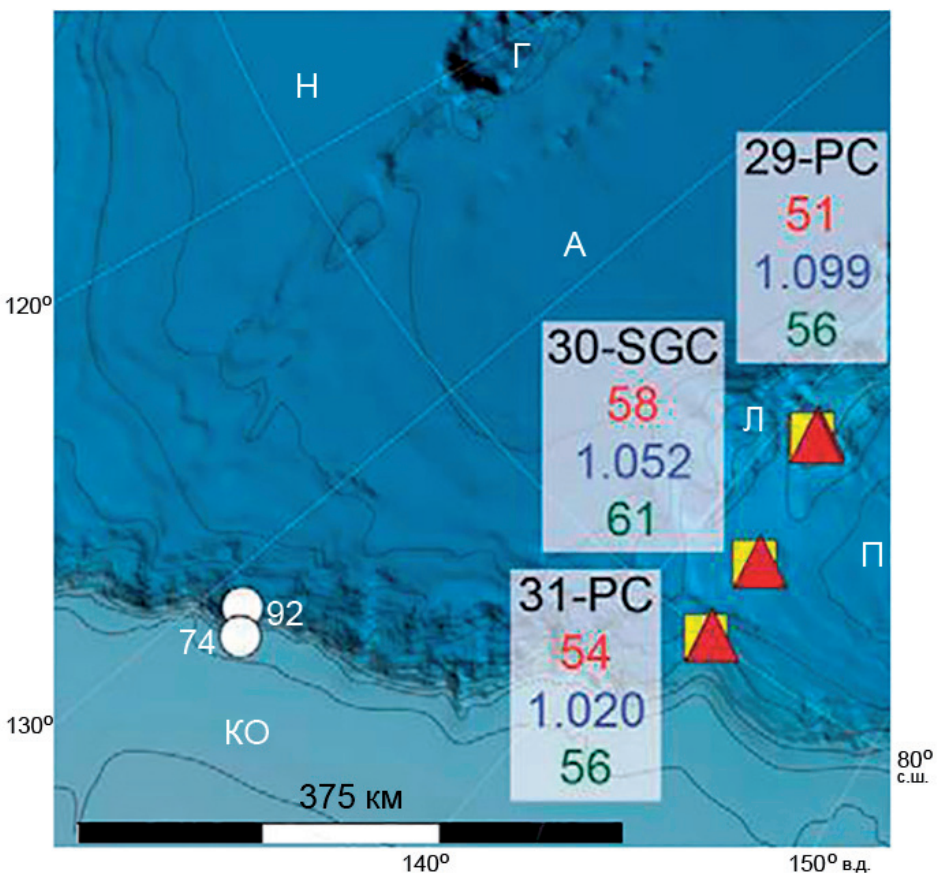

Рис. 2. Схема расположения станций замера теплового потока.

Показаны пункты измерения теплового потока (красные треугольники), по (O’Regan et al., 2016); желтые квадраты - грунтовые станции; тепловой градиент (цифры красным), средняя теплопроводность (цифры синим) и тепловой поток (цифры зеленым); пункты измерения теплового потока (белые кружки с цифрами), по (Stranne et al., 2016).

Обозначено: Н - котловина Нансена, Г - хр. Гаккеля, А - котловина Амундсена, Л - хр. Ломоносова, П - котловина Подводников, КО - континентальная окраина Евразии.

Fig. 2. Scheme of heat flow measurement stations.

Heat flow measurement points are shown (red triangles), after (O'Regan et al., 2016); yellow squares - ground stations; thermal gradient (numbers in red), average thermal conductivity (numbers in blue) and heat flux (numbers in green); heat flow measurement points (white circles with numbers), after (Stranne et al., 2016).

Designated: H - Nansen basin, $\Gamma$ - ridge. Gakkel, A - Amundsen basin, Л - ridge. Lomonosov, П - Podvodnikov basin, $\mathrm{KO}$ - continental margin of Eurasia. 
Немногочисленные станции измерения теплового потока, размещение которых попало в полосу влияния ХЛЗ в районе южного крайнего звена хр. Ломоносова (в зоне его контакта с прогибом Северным), демонстрируют небольшой, но заметный пик на профиле расположения станций (красные треугольники), связанный с тепловой аномалией: $(56 \pm 6-53 \pm 11)-(61 \pm 12)-(56 \pm 6) \mathrm{mW} / \mathrm{m}^{2}$ (O’Regan et al., 2016) (значения с севера на юг, рис. 2). Восточнее $130^{\circ}$ в.д. практически на бровке шельфа обращенной к котловине Амундсена две станции (белые кружки) зафиксировали значения от 74 до $92 \mathrm{~mW} / \mathrm{m}^{2}$ (Stranne et al., 2016).

Эпицентры землетрясений также зафиксированы вдоль рассматриваемой зоны разломов. На схеме, приведенной в работе (Имаева и др., 2007), ряд эпицентров за период 1909-2003гг располагается непосредственно в полосе ХЛЗ, начиная от о-ва Песчаный (устье Хатангского залива) и далее на бровке шельфа восточнее осевой зоны хр. Гаккеля (рис. 3 a).

Из другой, более обновленной схемы (рис. 3 б) (Богоявленский, 2019) следует, что концентрация и интенсивность землетрясений заметно выше к юго-западу от места пересечения ХЛЗ с продолжением осевой линии хр. Гаккеля. В этой части ХЛЗ сейсмичность тяготеет к ее тыловому ограничению, доходя до устья Хатангского залива. Тогда как на северо-восточном фланге ХЛЗ эпицентры землетрясений проявились вдоль внешней стороны рассматриваемой зоны разломов, практически на склоне котловины Амундсена, протягиваясь до хр. Ломоносова, но их интенсивность заметно слабее, чем отмеченных выше. Такое распределение в локализации эпицентров относительно ХЛЗ, как видно, напоминает пропеллерообразный характер. Это свидетельствует о различиях в современной геодинамической активизации юго-западного (Западно-Лаптевский рифтогенный бассейн) и северо-восточного фланга зоны разломов (обращенного к котловине Амундсена), обусловленной дисимметрией в развитии южного (прилаптевоморского) отрезка осевого спредингового центра хр. Гаккеля. Подтверждением этому служат как локализация очагов землетрясений, так и фокальные механизмы отдельных землетрясений, приведенные на схеме сейсмотектоники (Имаева и др., 2017). Однако следует подчеркнуть, что высказанные соображения о локализации землетрясений основаны на данных весьма редкой сети сейсмологических станций, а потому с ограниченной зоной охвата территорий, по причине чего большая часть арктического региона (включая шельф Восточной Арктики), ошибочно считается «немой» в отношении сейсмичности (Богоявлен-
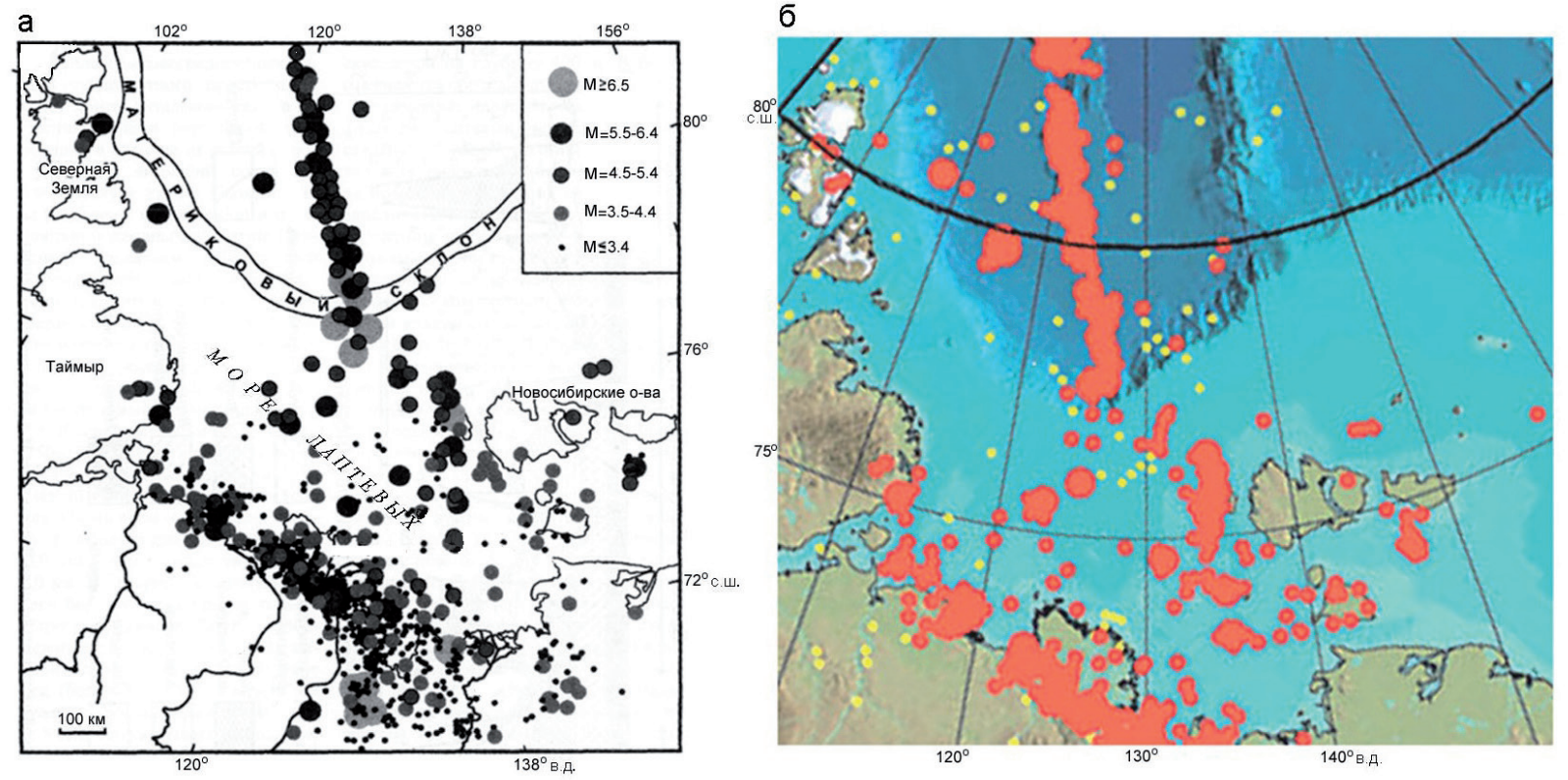

Рис. 3 а, б. Схемы эпицентров землетрясений шельфа моря Лаптевых и прилегающих районов. а) - за 1909-2003 гг. c M=3.4-7.0 по (Имаева и др., 2007). б) - карта землетрясений по (Богоявленский, 2019).

Fig. 3 a, b. Diagrams of earthquake epicenters on the Laptev Sea shelf and adjacent areas. a) - for 1909-2003 years with $\mathrm{M}=3.4-7.0$ to (Imaeva et al., 2007). b) - earthquake map according to (Bogoyavlensky, 2019). 


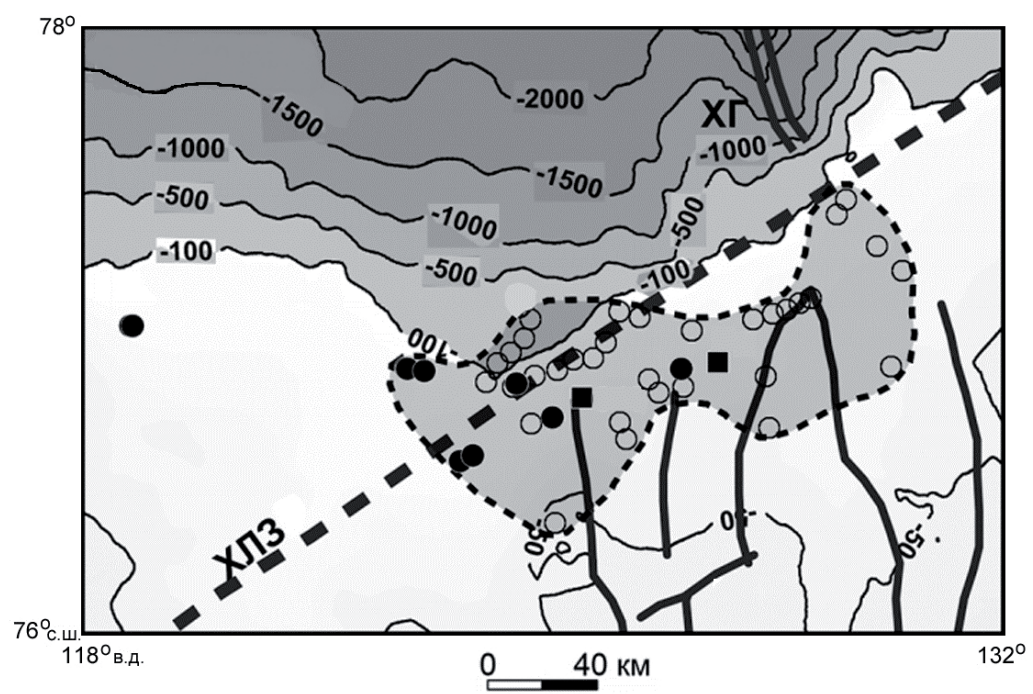

Рис. 4. Область проявления метановых сипов (пунктирный контур) на батиметрической схеме моря Лаптевых и некоторые разломы по (Баранов и др., 2019). ХЛЗ - Хатангско-Ломоносовская зона разломов, ХГ - хребет Гаккеля.

Fig. 4. Area of occurrence of methane seeps (dotted contour) on the bathymetric scheme of the Laptev Sea and some faults after (Baranov et al., 2019). ХЛЗ - Khatanga-Lomonosov fault zone, ХГ - Gakkel ridge.

ский, 2019; Рогожин и др., 2015). Естественно, что такое упрощенное восприятие представлений о сейсмичности не позволяет объективно подойти к оценке сейсмотектонических событий.

Имеющиеся данные по расположению сиповых полей разгрузки метана и выделение их общего ареала распространения размером $190 \times 90$ км (Баранов и др., 2019; Сергиенко и др., 2012) показывают приуроченность последнего не столько к району проникновения хр. Гаккеля в пределы Лаптевоморской континентальной окраины, сколько его тяготение к выше отмеченным полям концентраций эпицентров землетрясений локализованным вдоль юго-западного фланга ХЛЗ (рис. 4). Таким образом, не исключено, что сосредоточенные здесь эпицентры землетрясений (рис. 3) могут выступать в качестве триггера сиповой разгрузки метана, учитывая многочисленность проявлений этих процессов в Восточной Арктике (Масуренков и др., 2013; Сергиенко и др., 2012 и др.).

\section{Заключение}

Интерпретационный анализ материалов сейсмических исследований (Шипилов и др., 2019; 2020) показывает, что наиболее активные сдвиговые смещения по ХЛЗ происходили в меловое раннекайнозойское время. После этого спрединг в Евразийском бассейне упал до медленного и ультрамедленного (Лобковский и др., 2020) и движения по ХЛЗ практически незаметны, но судя по рисунке 3 , сопровождаются слабой сейсмичностью на СВ фланге этой зоны в котловине Амундсена. Тогда как ЮЗ фланг ХЛЗ отличается повышенной сейсмичностью, что подчеркивается выявленной современной геодинамической активизацией (Баранов и др., 2018), характеризующейся горизонтальными сдвиговыми смещениями.

Таким образом, приведенные данные свидетельствуют о том, что, несмотря на ультрамедленный спрединг в Евразийском бассейне, ХЛЗ находит отражение не только в данных батиметрии и потенциальных геофизических полях, но и подтверждается материалами глубинных исследований литосферы, сейсмологическими наблюдениями, приуроченностью сиповых полей разгрузки метана и, хотя и не многочисленными, теплометрическими показателями.

Исследование выполнено при финансовой поддержке РФФИ в рамках научного проекта № 18-05-70012, код «Ресурсы Арктики». 


\section{Литература}

1. Баранов Б.В., Лобковский Л.И., Дозорова К.А., Цуканов Н.В. Система разломов контролирующих метановые сипы на шельфе моря Лаптевых // ДАН. 2019. Т. 486. № 3. С. 354-358. DOI: https://doi. org/10.31857/S0869-56524863354-358.

2. Баранов В. Б., Флинт М. В., Римский-Корсаков Н. А. и др. Структурные свидетельства современной активности Хатангско-Ломоносовской зоны разломов в море Лаптевых // ДАН. 2018. Т. 480. № 3. C. 344-347. DOI: 10.7868/S0869565218150185.

3. Богоявленский В.И. Формирование залежей углеводородов в верхней части разреза и кратеров выбросов газа // Нефтегаз. 2019. № 1(85). С. 48-55.

4. Имаева Л.П., Гусев Г.С., Имаев В.С. и др. Геодинамическая активность новейших структур и поля тектонических напряжений северо-востока Азии // Геодинамика и тектонофизика. 2017. Т. 8. № 4. С. $737-768$. DOI:10.5800/GT-2017-8-4-0315.

5. Имаева Л.П., Имаев В.С., Козьмин Б.М. и др. Новейшие структуры, стратиграфия квартера и современная геодинамика территории арктического сектора прибрежно-шельфовой зоны Северного Верхоянья (северо-восток Якутии) // Бюллетень комиссии по изучению четвертичного периода. 2007. № 67. С. 6-19.

6. Лобковский Л.И., Кононов М.В., Шипилов Э.В. Геодинамические причины возникновения и прекращения кайнозойских сдвиговых деформаций в Хатанга-Ломоносовской разломной зоне (Арктика) // Доклады РАН. Науки о Земле. 2020. Т. 492. № 1. C. 82-87. DOI: 10.31857/S2686739720050102.

7. Масуренков Ю.П., Слёзин Ю.Б., Собисевич А.Л. Газовые шлейфы у острова Беннетта // Изв. РАН. Серия географическая. 2013. № 3. С. 86-95.

8. Рогожин Е.А., Антоновская Г.Н., Капустян Н.К. Современное состояние и перспективы развития системы сейсмического мониторинга Арктики // Вопросы инженерной сейсмологии. 2015. Т. 42. № 1. С. 58-69.

9. Сергиенко В.И., Лобковский Л.И., Семилетов И.П. и др. Деградация подводной мерзлоты и разрушение гидратов шельфа морей Восточной Арктики как возможная причина «метановой катастрофы»: некоторые результаты комплексных исследований 2011 года // ДАН. 2012. Т. 446. № 3. С. 330-335.

10. Шипилов Э.В., Кириллова Т.А. Тектоника зоны сочленения Евразийского бассейна и хребта Ломоносова с континентальной окраиной Сибири // Труды Ферсмановской научной сессии ГИ КНЦ РАН. 2020. № 17. C. 563-567. DOI: 10.31241/FNS.2020.17.109.

11. Шипилов Э.В., Лобковский Л.И., Кириллова Т.А. О тектоно-геодинамических взаимоотношениях Евразийского бассейна и хребта Ломоносова с континентальной окраиной Сибири по новым сейсмическим данным // Арктика: экология и экономика. 2020. № 4(40). С. 34-42. DOI: 10.25283/2223-45942020-4-34-42.

12. Шипилов Э.В., Лобковский Л.И., Шкарубо С.И. Хатангско-Ломоносовская зона разломов: строение, тектоническая позиция, геодинамика // Арктика: экология и экономика. 2019. № 3 (35). C. 47-61. DOI: 10.25283/2223-4594-2019-3-47-61.

13. Corchete V. 3D imaging of the crust and upper mantle beneath the Arctic Ocean from Rayleigh-wave groupvelocity analysis // Geological Journal. 2019. 54. P. 1-9. DOI: 10.1002/gj.3151.

14. O’Regan M., Preto P. , Stranne C. et al. Surface heat flow measurements from the East Siberian continental slope and southern Lomonosov Ridge, Arctic Ocean // Geochem. Geophys. Geosyst. 2016. 17. P. 1-15. DOI: $10.1002 / 2016 \mathrm{GC} 006284$.

15. Stranne C., O'Regan M., Dickens G. R. et al. Dynamic simulations of potential methane release from East Siberian continental slope sediments // Geochem. Geophys. Geosyst. 2016. V. 17. P. 872-886. DOI:10.1002/2015GC006119. 